A vastly revised and updated version of this preprint is available as a chapter in a book titled: Reorientation of activities and self-environment integration: A new theory of activities. The book is available from https://www.amazon.com/dp/9357738096.

\section{Why do we need a robust theory of activities?}

\section{Introduction}

While discussing a theory of human activities, we will take a broadest possible view of activities, and for our purpose, whatever little action we undertook-during previous 24 hours, or during last week or month-every bit can be included in our activities like sleeping, breathing, eating, drinking, thinking, walking, worrying, getting angry, watching TV, and rest of the mundane things including sex. Thus, our activities make us a unique human being.

An intervention based on such a broad model would naturally change multiple activities - and its brief working definition could be: an intervention that empowers the individuals for simultaneously and systematically changing their multiple activities. Such an empowered person can (and it is hoped that she will) strive to become a better-quality individual through-out her life-and thus multiple dimensions of society would improve. So, we can add to the definition that such an empowered person has a lifelong choice but not the obligation to improve herself and become a better-quality individual. Enriching the quality influences our physical, mental, and social wellbeingthat would make any such intervention a powerful tool for improving health and healthcare practices.

\section{1-1. What do we mean by simultaneous and systematic change in multiple activities?}

\footnotetext{
* Retired Professor

Nagpur, Central India

Email: nagpor@gmail.com
}

We are comfortable with a convention view of our activities, dividing them in terms of behaviours, thinking, and feelings. While behaviours such as smoking or watching television can be observed, thinking and feelings (such as anger) sometimes can be judged by accompanying behavioural attributes. The three are interlinked-and cognitive behaviour therapy the most influential form of psychotherapy today, is "based on the notion that modifying maladaptive cognitions can lead to a decrease in emotional distress and problematic behaviors". "This conventional view forces us to categorize individuals as smokers or non-smokers, and as anxious or depressed. Many hundreds of such categories have been devised and analysed in scientific literature. It may be shocking to some of us, but these widely practiced approaches are unhelpful ${ }^{2}$, and we need a more robust model of our activities.

Let us take the example of a farmer, a shopkeeper, and a manager. What is common between them? A farmer knows that crops need weeding. If weeding is not done water, nutrients, and even sunshine shall be shared by weeds leading to stunted growth of crops. The shopkeeper needs to replace slow moving items with fast moving items. Both are competing for the limited shelf space. A manager has limited budget for spending on staff. He would rather spend It on efficient employees. Any manager worth his name shall try to weed out inefficient employees.

How are these examples relevant to our own life? Human beings have activities. We need to weed out activities that are harmful and even those that are useless. Other-

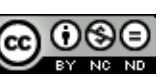

Attribution-NonCommercial-NoDerivs CC BY-NC-ND

Copyright is with the author. Downloading and sharing of this article is allowed, as long as the author is credited. But changes or commercial uses are not allowed.

This preprint has not been peer reviewed. Author reports no conflict of interest. Date of creation: 12 July, 2020

Suggested citation: Agarwal A. Why do we need a robust theory of activities? [Internet]. PsyArXiv; 2020. Available from: https://psyarxiv.com/fr2uy

DOI: https://doi.org/10.31234/osf.io/fr2uy 


\section{A simple model of activities}

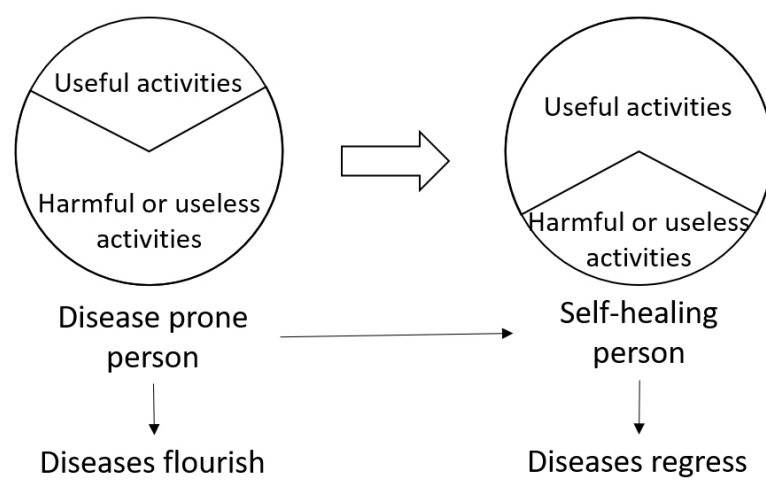

wise useful activities shall not flourish, simply because there are not enough resources left with the individual. We are very well aware of these principles. Unfortunately, such ideas appear to be old-fashioned and unscientific-as we do not own a scientific model promoting useful activities.

\section{1-2. Activities of a self-healing person and activities of a disease-prone person}

Activities have a strong bearing on our health. However, conventional epidemiological perspectives continue to consider only a few activities as relevant. The so-called risk factors are further divided into categories such as unhealthy behaviours, work related determinants, and psychological factors. Lack of physical activity, sedentary habits, smoking, unhealthy eating, excessive alcohol intake, and unsafe sex-these are some behaviours that are prime candidates for modification in every physician's mental list. At least for half a century now, patients also know that these behaviours would be frowned upon. Anxiety, depressive thoughts, hostility and excessive anger, acute and chronic stressful events, deprivation particularly in early life, social isolation, and social or workplace discrimination are some of the psychosocial factors generally considered relevant to disease causation, persistence, and exacerbation.

However, this conventional risk factor approach has been considered too narrow. Friedman wanted us to have a capacious all-inclusive focus-and introduced two antithetical personality constructs termed disease-prone and self-healing personalities. ${ }^{3}$ It is our overall activities that represent or make our personalities. So, the constructs of Friedman can be paraphrased as-activities of a disease-prone person and activities of a self-healing person. The ongoing argument in this paper is that a disease-prone person can become a self-healing person (Figure-1), and this qualitative change can be curative also. So, a disease can be healing simultaneously, while a disease prone person is becoming a self-healing person. Thus (as expected) a comprehensive change in activities can bring about a fundamental change in the individual.

Self-healing and disease-prone, are they valid con- structs - and why should they have our attention? Let us examine, whether today's dominant theories are adequate or inadequate to meet our needs. Friedman's argument was that so-called risk factors mostly do a poor job of predicting who will succumb. He iterated, "Most cookie lovers do not develop breast cancer, most couch potatoes do not suffer strokes, and it is even the case that most smokers do not develop lung cancer." While more than a hundred years of personality research has given us a general verdict that "a person who is chronically irritated, depressed, hostile, impulsive, bored, frustrated, lonely, or powerless is indeed more likely to develop illnesses and to die prematurely than is someone who generally feels emotionally balanced and effective, is in a satisfying job, has stable and supportive social relationships, and is well integrated into the community". Through his constructs, Friedman wanted to "direct theory and research away from associations between single predictors and single outcomes, focusing instead on multiple-predictor, multiple-outcome developments over long periods of time".

There is something more that makes Friedman's personality constructs interesting. Research has "generally found that similar sorts of individual differences were simultaneously relevant to a wide array of health outcomes". ${ }^{3}$ This may simply mean that the causation (and therefore treatment) of many disorders could be possible on widely similar lines-say by converting a disease-prone person to self-healing person, as and when it is attempted through a broader change in activities. In a very similar context, we are deliberating on transdiagnostic (meaning across diagnoses) approaches to aetiological and therapeutic aspects of medically unexplained symptoms and syndromes ${ }^{4}$, and psychological disorders 5 . That may be a reflection of a fundamental shift beginning in our thinking that still considers every disease different in its causation and requiring a specific treatment.

\section{1-3. A very simple model of activities}

Thus, we can think of a very simple model of our activities. In this model our activities are divided into two categories 'useful' and 'harmful or useless'. This is a quantitative model. When useful activities are less, as is the case of 
a disease-prone person, the diseases would flourish. When useful activities are more, as is the case of self-healing person, the diseases would regress. This is a very intuitive model, based on the examples of farmer, shopkeeper, and manager that have been given above. However, two problems are obvious: Firstly, there is no simple way of categorizing our activities as useful, and useless or harmful. For example, sleeping is useful, but excessive sleep is not. Secondly, we have no practical method of quantifying the two different categories of activities. For a workable model, these two problems need to be sorted out. But such a model shall endeavour to direct theory and research away from individual risk factors and away from ill-defined and poorly-defined illnesses, bringing into focus constructs closer to self-healing - how to stay healthy, and if lost how to regain health with simple measures and at a low cost.

Encouraged by the success of transdiagnostic approaches across psychological conditions, some investigators are trying them for medically unexplained symptoms. ${ }^{4}$ In this trial, however, the subjects would continue to receive standard medical care provided by "specialised medical staff". Therefore, the treatment becomes individualized and specific, and transdiagnostic becomes a misnomer-or at least its purpose is defeated.

On the other hand, the activities model (Figure-1) is intended to be nonspecific and powerful enough so as to lead to regression of common psychological diseases and medically unexplained conditions. Such approach (of converting a disease-prone person to a self-healing person) would not need the standard medical care and may prove valuable in simplifying the current chaos created by a plethora of ineffective approaches. After treatment is unified, there will be little justification in keeping multiple diagnostic labels, and my feeling is that many disorders will get merged into single entities. With such a model in our hands, we would be moving towards demedicalization on a very large scale.

\section{1-4. Can diseases regress?}

Regression has been observed in conditions such as angina and coronary heart disease ${ }^{6}$, diabetes, and many types of cancers. Many infectious diseases including tuberculosis are known to regress spontaneously. Tuberculosis patients were sent to hill stations, before the discovery of anti-tubercular drugs. Type 2 diabetes is known to regress after weight loss $s^{7}$, and with intensive control ${ }^{8}$. Spontaneous regression of cancers has been observed, and possible mechanisms include elimination of carcinogens, psychological factors ${ }^{9}$, lifestyle changes ${ }^{10}$, and prayers ${ }^{11}$.

\section{1-5. Is it possible to have an intervention targeting multiple activities?}

Multiple health behaviour research is on our radar ${ }^{12}$, and interventions are being designed to promote multiple health behaviour change..$^{13}$ This research is trying to target multiple risky behaviours, but it is following the same old risk factor approach. Also, their focus is on prevention, while my focus is firmly on regression of disease. They are trying to define disease specific clusters of risky behaviours, while my approach is truly nonspecific. In view of what is being attempted and what has been achieved so far, my approach may be considered a big leap forward. It may also be considered difficult or even impossible.

Let us look at the difficulties of changing many or all of our activities. The sum total of these difficulties would be $=$ difficulties for changing activity $1+$ activity $2 \ldots+$ activity $n$. And we will consider the benefits of changing such large number of activities = benefits of changing activity $1+$ activity $2 \ldots+$ activity $n$. Then we are likely to think that changing many activities must be a very difficult intervention and practically its benefits will amount to nothing. However, the reality is that whole is not always equal to its parts-as Anderson ${ }^{14}$ argued, "More Is Different"- and while moving from less complex to more complex, "at each level of complexity entirely new properties [would] appear". Properties of water cannot be deciphered by the properties of its elements-and a painting is not the sum total of colours used by the painter. And as Anderson ended his argument and rested his case, the differences between the rich and poor cannot be reduced to the fact that the later have more money. Therefore, it may be far easier to change multiple activities together, and the benefits of changing large number of activities may be far in excess of our wildest anticipation.

\section{1-6. What would it mean for health and healthcare?}

Next genuine revolution in healthcare and many other areas must come through an intervention targeting our (multiple) activities. Theoretically speaking simple nonspecific lower-level activities-change interventions can replace specific, costly and inefficient higher-level interventions-thereby reducing the need of healthcare resources including the number of healthcare workers. Much of the healthcare can be taken away from the hands of the physicians (and other formally trained healthcare workers) and brought into domain of individuals and the society. This downsizing will have positive effect on the quality of healthcare workers in general and physicians in particular, as poor-quality medical colleges can be closed down.

\section{A simplified pathway of disease causation and dis- ease reversal}

A simplified model pertaining to health and disease is presented in Figure-2. At the bottom (Step-1) are societal factors. The activities of the individual are at Step-2. Governing and controlling (nervous, endocrine, and immune) 


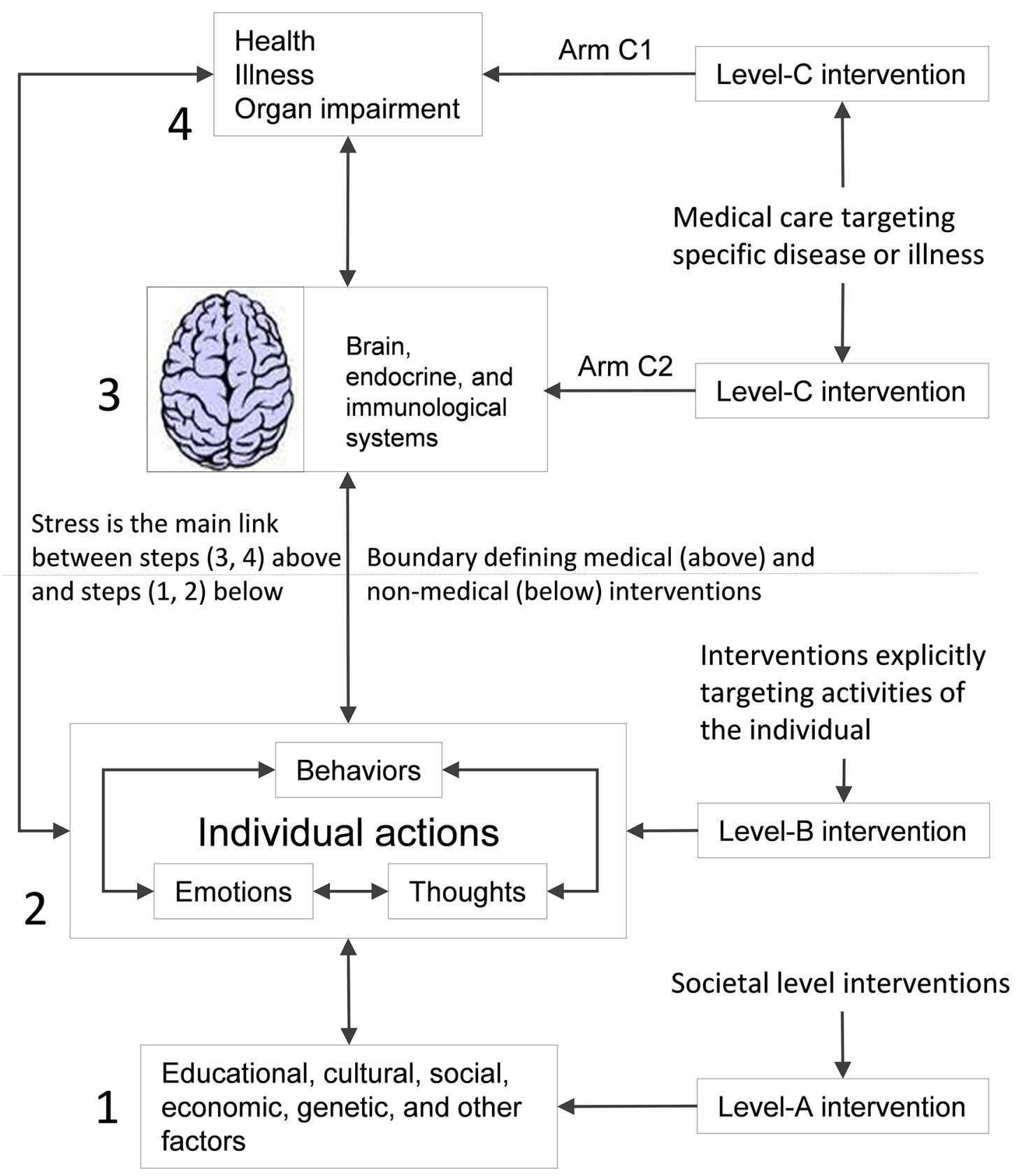

Figure-2. This depicts a simple four-step pathway of disease causation and reversal. Three levels of interventions act on these four steps. MACI is a Level-B intervention that acts on Step-2 of this- pathway. (Figure reused from: Agarwal A. In search of revolution: MACI strengthened health-care: Unpublished book; 2018.) 
systems of the body are at Step-3. Finally, at Step- 4 we find the resultant diseases affecting individual organs and systems of the body. It needs to be emphasized that bidirectional arrows interconnect these steps-for example social conditions influence our activities, and our activities influence social conditions. To extend this argument further, severe disease conditions of organs and systems (Step-4) will adversely influence the regulatory systems (Step-3) that will in turn adversely influence the activities (Step-2).

Generally speaking, this will be considered a pathway of disease causation. Then why do I call this a pathway of disease causation and disease reversal? It is because the same pathway will lead to regression and reversal of disease. Improvement in social conditions can lead to improvement in the activities. Improvement in activities can lead to a better regulated neuroendocrine-immune system that can in turn lead to regression and reversal of disease.

In this model, I have envisaged three levels of interventions-A, B, and C. What we consider healthcare consists of Level-C interventions directed against specific diseases. Level-A interventions are societal level interventions such as providing housing to the poor, safe drinking water, universal education, and employment generation. Level-B interventions are individual centric, directed at changing the activities of the individual (and not directed against any specific disease). The existent examples of such interventions are physical exercise, healthy food, Yoga, and meditation. This paper, however, envisages a more efficient and effective model of activities change (Figure-1).

\section{An activities-change intervention (Level-B) can replace Level-A interventions?}

"The biggest enemy of health in the developing world is poverty, and the struggle for health is part and parcel of the struggle for development." said Kofi Annan in World Health Assembly of $2001 .{ }^{15}$ In his last days Gandhi wrote in his diary ${ }^{16}$, "I shall give you a talisman. When faced with a dilemma as to what your next step should be, remember the most wretched and vulnerable human being you ever saw. The step you contemplate should help him!" In recent years a number of bold moves by Prime Minister Modi have started to touch the life of most vulnerable sections of our society. Some examples of these outreach initiatives are $100 \%$ rural electrification ${ }^{17}$, Pradhan Mantri Awas Yojana ${ }^{18}$, open defecation free India ${ }^{19-21}$, Pradhan Mantri Ujjwala Yojana ${ }^{22}$ 23, and Pradhan Mantri Jan Dhan Yojana. ${ }^{24}$ Significance of these Level-A interventions cannot be undermined. However, hundreds of such initiatives would not be enough, if the purpose is attainment of equity of health.

\section{2-1. The Status Syndrome: Why fulfilling basic necessities is not enough?}

Poverty has adverse health consequences, but a more challenging phenomenon exists. In a 2006 article, Marmot called this Status Syndrome ${ }^{25}$, a social gradient in health in individuals who cannot be considered poor: the higher the social position, the better the health.

Nearly forty years ago, first publications that drew our attention to the subject of social gradient and health inequalities conspicuously originated from UK. By analysing the data from the first Whitehall study of British civil servants Marmot had in 1978 for the first time showed that health followed a social gradient. ${ }^{26}$ Health disparity was evident across all four British employment grades: other, clerical, professional/ executive, and administrative. "Men in the lower employment grades were shorter, heavier for their height, had higher blood pressure, higher plasma glucose, smoked more, and reported less leisure-time physical activity than men in the higher grades."

After overall risk analysis, it was not surprising therefore: in comparison to the top (administrative) grade, those in the bottom grade showed 53 percent higher prevalence of angina and 77 percent higher prevalence of ischemic-type ECG abnormalities. After 7.5 yrs. of follow up, the coronary mortality was 3.6 times higher in the lowest than in the top grade. Rose and Marmot remarked in discussion: "Our most striking finding was the size of this social class effect: a man's employment status was a stronger predictor of his risk of dying from coronary heart disease than any of the more familiar risk factors".

It is not that the risk jumped suddenly, but the consistency is the concern with which it kept on rising across the grades: meaning executive/ professional grades had higher risk than administrative, but lower risk than clerical-while the other grade had highest risk of all. There is an eerie resemblance between Whitehall study data and what Erikson observed down the educational hierarchy in egalitarian Sweden. That individuals with a PhD had lower mortality than those with a master's degree, who had lower mortality than those with a bachelor's degree, and so on. ${ }^{27}$ Presently we can only speculate about some fundamental processes that seem to be at work in our society. Material deprivation is not the answer as to why someone with a master's degree should have greater mortality than a PhD. Similarly, material deprivation is not the cause why a professional should have greater mortality than an administrator.

\section{2-2. The alternate meanings of wealth and poverty}

Amartya Sen, a Nobel laureate economist, proposed a new meaning of wealth, before visiting the real meaning 
of poverty: "Economics is not solely concerned with income and wealth but also with using these resources as means to significant ends, including the promotion and enjoyment of long and worthwhile lives. If, however, the economic success of a nation is judged only by income and by other traditional indicators of opulence and financial soundness, as it so often is, the important goal of well-being is missed." 28

Sen is fond of talking about Kerala-home to less than three percent of India's population. Two decades ago, Kerala had (and still has ${ }^{29}$ ) the unique distinction of having highest life expectancy at birth among Indian states (74 against 63.5 for the whole of India). Amongst Indian states, Kerala is also the highest in Human Development Index. This distinction has been achieved, despite relative economic backwardness-and the achievement is presumably due to its low levels of economic and educational disparities. There is evidence to show that Kerala's population is most egalitarian among the Indian states. In $\mathrm{Hu}-$ man Development Index (2011 data), the average loss due to inequality is $32 \%$ at the All-India level. It is the highest for Madhya Pradesh (36\%) and the lowest for Kerala $(17 \%) .^{30}$ Kerala is perhaps the only state of India, where females outnumber males. Overall, the ratio is 0.93 in India. This shows the equality that women enjoy in Kerala.

Sen compared Black Americans with Keralites and Chinese, to show significant and persistent deprivation existed in a rich country like USA. And in the process, he was able to highlight the changed definition of poverty and deprivation across the world ${ }^{28,31}$. Black American men had lower survival prospects than both Chinese and Keralites. Black American women were slightly better than Chinese but fared worse than Keralites. This is insightful because Black Americans were immensely richer in income terms vis-à-vis people of China or Kerala (even after correcting for cost-of-living differences). So Black Americans were not poor by world standards, nevertheless they were poor.

Sen upped the ante by comparing Black American men living in Harlem with Bangladeshi men. Fewer than forty percent of Harlem men were likely to reach 65 years in comparison to more than 50 percent Bangladeshis. By US standards the Harlem men may have been poor, but they were much richer than Bangladeshi residents, even after necessary adjustments.

Sen also discussed the effects of high unemployment in Europe. The political establishment preferred to downplay the adverse effects of being jobless-arguing that there was no deprivation, as European system of social security and the unemployment insurance made up for the loss of income. Sen debunked such logic ${ }^{31}$ (p. 21): Unemployment is not merely a deficiency of income. It entails heavy fiscal burden on the state, and "it is also a source of far-reaching debilitating effects on the individual freedom, initiative, and skills. Among its manifold effects, unemployment contributes to the "social exclusion" of some groups, and it leads to losses of self-reliance, self-confidence and psychological and physical health." Thus, unemployment entails deprivations that are nowhere reflected in income distribution statistics.

So, poverty cannot be defined in monetary terms alone. Black Americans are poorer than Keralite Indians. This is a different kind of poverty that the unemployed in Europe also experience despite their social security and unemployment insurance. These poor from richer nations tell us a story that the poor of the poorest nations cannot tell-a story that highlights the alternate meaning of poverty.

\section{2-3. How are social disparities translated into health disparities?}

A complex web of factors links social disparities with health disparities. We have strong evidence that those at the lower social strata have unhealthy lifestyles: they are more likely to consume tobacco ${ }^{32,33}$ and energy rich unhealthy food ${ }^{34}$ (p. 158). Many other unhealthy behaviours such as unsafe sex, lack of physical activity or sedentary habits, and excessive alcohol intake can also have higher prevalence amongst disadvantaged or less privileged sections of society.

There is evidence that social support depends on the social class. ${ }^{35,36}$ Countries with greater income inequality have higher homicide rates and violence, because wide income differences are considered socially corrosive. Putnam $^{37}$ illustrated the inverse relation between economic inequality and social capital. During the early part of last century, in his view, the economic differences were narrow and community life was greater. So, the social support for the poor is declining, and this must be contributing to health disparities.

Stress is slowly emerging as an upstream link between social disparities and health inequalities. For a comprehensive view, the reader is referred to Brunner and Marmot. ${ }^{38}$ Stress is linked to unhealthy lifestyle choices. It is a common observation that, when under stress, people go for binge eating or drinking, and they smoke or indulge in other risky behaviours. This common observation has been scientifically validated. ${ }^{39}$

It has been argued that "social context early in life can have a strong influence on resources and opportunities (and, thus, on living and working conditions) at later stages". ${ }^{40}$ Thus adults, working in lower grades or having lower income or educational qualification, are likely to have a (life) long experience of a disadvantaged social position. Therefore, it is the long experience of social disadvantage 
or disadvantage beginning in early life that should be considered responsible for health inequalities, rather than the present social position or grade.

\section{2-4. Interventions based on ecological framework}

According to the ecological framework, people in the disadvantaged social position indulge in unhealthy behaviours. However, social ecological factors are in many ways responsible for such unhealthy behaviours. Thus, ecological framework seeks to "focus attention on the environmental causes of behavior and to identify environmental interventions", while focusing solely on individuals is considered "victim-blaming ideology". ${ }^{41}$ Besides the individual, other targets of change are public policy, community, workplace or the organization, and social norms or influences. But the objectives remain the same that is promoting healthy behaviours such as quitting tobacco, physical activity, safe sex, and healthy food. Therefore, differences between individually-focused and ecologically focused health promotion strategies are subtle. And the interventions based on ecological framework may be Level-A interventions (directed at environment), or a mix of Level-A and Level-B interventions (directed both at the individual and the environment).

\section{2-5. Improving activities can mitigate the effects of social disparities}

Social gradient, status syndrome, or a different meaning of poverty-they all convey social inequality that compromises the equity of health. We have broadly understood the mechanisms linking social disparity and resulting health disparities-and only improved activities can break these links.

Mitigating the effects of social disparities would require dealing with stress, social isolation, unhealthy behaviours, and living and working conditions. This will require large scale changes in activities. Let us take the example of an unskilled casual labourer, who is an alcohol and tobacco user and indulges in domestic violence. He is socially isolated and not covered by any health insurance. His family faces a real risk of health and economic disasters. Thus, he is facing multiple problems and traditional interventions would be of little use for him. Only hope can be an intervention based on activities model that reduces multiple harmful activities, increase useful activities, and converts disease-prone person to a self-healing person (Figure-1).

Ecosystem gets changed, if and when a large number of individuals improve their activities
Health promotion at the individual level may amplify socio-economic differences in health. Concerted political action is needed for improving the health of whole populations, especially that of disadvantaged subgroups. ${ }^{42} \mathrm{Mac}-$ Donald also argues that medical breakthroughs "have, if anything, widened the inequity gap further. For what we have witnessed is the already moderately healthy becoming healthier yet, while similar levels of progress have been far less evident among those already most deprived. In other words, it has not been through lack of knowledge, so much as through lack of wisdom (and certainly lack of morality) in applying what we know, that we have caused the problem we face now." ${ }^{33}$ Baum calls for policy changes and advocacy for addressing deeper structural reforms in social, political, economic, and other spheres. ${ }^{44}$ Such calls are not new. Nearly 70 years ago, Radhakrishnan ${ }^{45}$ called for spiritual reawakening of the human kind, a recovery of faith, far deeper than any social, political, or economic adjustment.

To change this faulty ecosystem, we need to improve multiple dimensions of our society-while every individual needs to contribute, some need to become the leaders. A new theory of activities has been conceptualized. ${ }^{46}$ That envisages some individuals becoming better quality individuals and lead the challenge of changing the existing systems.

\section{An activities-change intervention (Level-B) can replace Level-C interventions?}

Leaving aside Level-A and $\mathrm{B}$, the rest are all Level-C interventions. Since Level-A and Level-B interventions are by definition non-specific and non-medical, Level-C interventions are supposed to be medical, specific, and directed against particular disease entities. This supposition about specificity is only partially true or may be entirely untrue. Whether medical or surgical all treatments have non-specific effects and placebo actions. Even an antibiotic, acting against deadly bacteria, has a placebo effect. Psychotherapies, supposedly acting against specific psycho- pathology, have non-specific components such as personality of the therapist, therapeutic alliance, and the adherence to a protocol. Manner of the physician and good communication are part of the art of medicine that have powerful non-specific effects. Most of the beneficial effects, related to complementary and alternative treatments, are suspected to be due to powerful but non-specific placebo actions.

We must look at Hyland's classic discussion ${ }^{47}$ (pp. 207246)-how so-called specific treatments (belonging to both modern and alternative medicine) have a powerful nonspecific arms, and that 'nonspecific' element may be partially or even entirely responsible for the beneficial effects of the 'specific' treatments. We may be apt to con- 
sider nonspecific to be less important or the other part of therapy. But Hyland (p. 2) found that the "[other part] explains at least $80 \%$ of the improvement that occurs when patients take antidepressants; it accounts for about $90 \%$ of improvement from psychotherapy (some suggest even more); and in the case of complementary and alternative medicine it accounts for between $80 \%$ and $100 \%$ depending on the therapy and controversial conclusions of those working in this field."

So, This model divides Level-C into indistinguishable but valid $\mathrm{C} 1$ (specific) and C2 (nonspecific) arms (Figure-2). The relative strength of these arms may vary from intervention to intervention. And at least in some interventions the $\mathrm{C} 1 \mathrm{arm}$ may be non-existent. As shown, $\mathrm{C} 2$ the nonspecific arm acts on the nonspecific Step-3 of causal pathway. This $\mathrm{C} 2$ arm acts as a placebo-and is liable to be replaced by a powerful Level-B intervention. Few of the treatments that will fall in this (dominant $\mathrm{C} 2 \mathrm{arm}$ ) category are: psychotherapies, many of the psycho-pharmaceuticals including antidepressants, backache remedies. Much of the complementary and alternative medicine will fall in this category. With a powerful Level-B intervention replacing such remedies, treatment of many conditions will be simplified. These include depression and other common psychological disorders, backache, asthma, coronary artery disease, and medically unexplained symptoms. These conditions together constitute a very large chunk of ill-health, and I have not made a complete list here.

\section{The bigger picture}

This paper looks at a four-step causal and reversal pathway. The super highway to disease may well become the super highway to health, depending on the choices that we make. 'We' includes the individual, the family, the society, the business, the political establishment, and the international community. Unfortunately, in this context, the choices that the individual is making are becoming and more and more peripheral.

Nestle ${ }^{48}$ asked, "Do food and beverage companies bear some responsibility for the food choices of individuals?" She argued: when confronted with their marketing tactics, we as individuals stood little chance to eat the food that was in our best interests. South Korea, Norway, Sweden, and England have passed laws, banning or restricting food advertisements, particularly those targeting children. USA and Australia want the food industry to go for responsible self-regulation. But Financial Times reported that McDonald's was set to double number of its restaurants in China. Will Indian policy makers go ahead to restrict the promotional activities of food companies? India and China, together accounting for more than one third of the world's population, must show leadership in this field.

It is widely believed that tobacco giants had a say in
India's tobacco-control policy, and even parliamentary committees deciding on tobacco were staffed by tobacco barons. ${ }^{49}$ These things are changing, with anti-tobacco campaign becoming shriller. But more things change, more they remain the same. Many people, including children, work in hazardous workplaces. Occupational medicine is long recognized a separate branch of medicinebut the individuals and the families continue to suffer, as it is not easy to quit a breadwinning job merely because of its risk potential. Air or water, where we live, may be getting increasingly polluted. Our neighborhoods may be noise, crime, or violence infested. Urban planning in a densely populated megacity can influence our wellbeing, as living in areas with walkable green spaces has shown to increase the longevity of senior citizens independent of their age, sex, marital status, baseline functional status, and socioeconomic status..$^{50}$ These arguments may and will look trite-but without empowering the individual to address these and many more such issues, the important objective of equity in health cannot be achieved. It is hoped that powerful Level-B interventions would prepare the individuals for improving the quality of the self-and for multiple collective actions for the larger good of the humanity and the environment. It can be argued that Level-A interventions are also influenced by the individualsand if we look at Figure-2 again, we will find individual (and her activities) at the centre of a hub. Developing and adopting a robust model of activities should become our foremost priority.

\section{References}

1. Hofmann SG, Sawyer AT, Fang A. The Empirical Status of the "New Wave" of Cognitive Behavioral Therapy. Psychiatric Clinics of North America. 2010;33(3):701-10.

2. Friedman HS. Personality, disease, and self-healing. In: Friedman HS, Silver RC, editors. Foundations of Health Psychology. New York: Oxford University Press; 2007. p. 172-99.

3. Friedman HS. The multiple linkages of personality and disease. Brain, behavior, and immunity. 2008;22(5):668-75.

4. Chalder T, Patel M, James K, Hotopf M, Frank P, Watts $\mathrm{K}$, et al. Persistent physical symptoms reduction intervention: a system change and evaluation in secondary care (PRINCE secondary) - a CBT-based transdiagnostic approach: study protocol for a randomised controlled trial. BMC Psychiatry. 2019;19(1):307.

5. Kring AM, Sloan DM, editors. Emotion Regulation and Psychopathology: A Transdiagnostic Approach to Etiology and Treatment. New York: The Guilford Press; 2010.

6. Ornish D, Scherwitz LW, Billings JH, Brown SE, Gould KL, Merritt TA, et al. Intensive lifestyle changes for reversal of coronary heart disease. JAMA. 1998;280(23):2001-7.

7. Ardestani A, Rhoads D, Tavakkoli A. Insulin cessation and diabetes remission after bariatric surgery in adults with insulin-treated type 2 diabetes. Diabetes Care. 2015;38(4):659-64. 
8. McFarlane SI, Chaiken RL, Hirsch S, Harrington P, Lebovitz HE, Banerji MA. Near-normoglycaemic remission in African-Americans with Type 2 diabetes mellitus is associated with recovery of beta cell function. Diabet Med. 2001;18(1):10-6.

9. Papac RJ. Spontaneous regression of cancer: possible mechanisms. In Vivo. 1998;12(6):571-8.

10. Ornish D, Weidner G, Fair WR, Marlin R, Pettengill EB, Raisin CJ, et al. Intensive lifestyle changes may affect the progression of prostate cancer. J Urol. 2005;174(3):1065-9; discussion 9-70.

11. Chang WY. Complete spontaneous regression of cancer: four case reports, review of literature, and discussion of possible mechanisms involved. Hawaii Med J. 2000;59(10):379-87.

12. Morabia A, Costanza MC. Clustering of risk factors: Buzz or signal for action? Preventive medicine. 2006;42(5):327-8.

13. Morabia A, Costanza MC. Multiple health behavior change research: en avant, March! Preventive medicine. 2008;46(3):179-80.

14. Anderson PW. More is different. Science. 1972;177(4047):393-6.

15. POVERTY BIGGEST ENEMY OF HEALTH IN DEVELOPING WORLD, SECRETARY-GENERAL TELLS WORLD HEALTH ASSEMBLY: World Health Organization; [17 May 2001]. Available from: https:// www.un.org/press/en/2001/sgsm7808.doc.htm.

16. Pyarelal. Mahatma Gandhi-The Last Phase. Ahmedabad: Navajivan Publishing House; 1958.

17. Agrawal A, Kumar A, Joji RT. 100\% Rural Electrification in India: Myth or Reality? In: Gupta A, Dalei N, editors. Energy, Environment and Globalization. Singapore: Springer; 2020.

18. Arora S. Upgrading Slums and Housing for Sustainable Urbanisation. 2019(2):20-3\%V 1.

19. Exum NG, Gorin EM, Sadhu G, Khanna A, Schwab KJ. Evaluating the declarations of open defecation free status under the Swachh Bharat ('Clean India') Mission: repeated cross-sectional surveys in Rajasthan, India. 2020;5(3):e002277.

20. Patwa J, Pandit N. Open Defecation-Free India by 2019: How Villages are Progressing? Indian J Community Med. 2018;43(3):246-7.

21. Ramani SV. On consortium driven sanitation interventions to end open defecation: insights from an Indian village study. Innovation and Development. 2019:1-17.

22. Gould CF, Urpelainen J. The Gendered Nature of Liquefied Petroleum Gas Stove Adoption and Use in Rural India. The Journal of Development Studies. 2019:1-21.

23. Mittal N, Mukherjee A, Gelb AJCfGDRfhwcosdff-s-r-cip. Fuel subsidy reform in developing countries: Direct benefit transfer of LPG cooking gas subsidy in India. 2017.

24. Kar B. Rural Business Owners, Banker and Services: A Behaviour Model. 2019;46(4):219-34.

25. Marmot MG. Status Syndrome: A Challenge to Medicine. JAMA. 2006;295(11):1304-7.

26. Marmot MG, Rose G, Shipley M, Hamilton PJ.
Employment grade and coronary heart disease in British civil servants. Journal of epidemiology and community health. 1978;32(4):244-9.

27. Erikson R. Why do graduates live longer? In: Jonsson JO, Mills C, editors. Cradle to Grave: Life-Course Change in Modern Sweden. Durham, England: Sociology Press; 2001.

28. Sen A. The Economics of Life and Death. Scientific American. May 1993:40-7.

29. Suryanarayana MH, Agrawal A, Seeta Prabhu K. Inequality-adjusted Human Development Index for India's States. New Delhi: United Nations Development Programme; 2011.

30. India State-Level Disease Burden Initiative C. Nations within a nation: variations in epidemiological transition across the states of India, 1990-2016 in the Global Burden of Disease Study. Lancet. 2017;390(10111):2437-60.

31. Sen A. Development as Freedom. New York: Alfred A. Knopf; 1999.

32. Jarvis MJ, Wardle J. Social patterning of individual health behaviours: the case of cigarette smoking. In: Marmot M, Wilkinson RG, editors. Social Determinants of Health. Second ed ed. London: Oxford University Press; 2006.

33. Bhan N, Karan A, Srivastava S, Selvaraj S, Subramanian SV, Millett C. Have Socioeconomic Inequalities in Tobacco Use in India Increased Over Time? Trends From the National Sample Surveys (2000-2012). Nicotine Tob Res. 2016;18(8):1711-8.

34. Robertson A, Tirado C, Lobstein T, Jermini M, Knai C, Jensen JH, et al., editors. Food and health in Europe: a new basis for action. Geneva: World Health Organization; 2004.

35. Geckova A, van Dijk JP, Stewart R, Groothoff JW, Post D. Influence of social support on health among gender and socio-economic groups of adolescents. European journal of public health. 2003;13(1):44-50.

36. Turner RJ, Marino F. Social support and social structure: a descriptive epidemiology. J Health Soc Behav. 1994;35(3):193-212.

37. Putnam RD. Bowling alone: collapse and revival of American community. New York: Simon and Schuster; 2000.

38. Brunner E, Marmot M. Social organization, stress, and health. In: Marmot M, Wilkinson RG, editors. Social Determinants of Health. Second ed. London: Oxford University Press; 2006. p. 6-30.

39. Walsh JL, Senn TE, Carey MP. Longitudinal associations between health behaviors and mental health in low-income adults. Translational behavioral medicine. 2013;3(1):104-13.

40. Braveman P, Barclay C. Health disparities beginning in childhood: a life-course perspective. Pediatrics. 2009;124 Suppl 3:S163-75.

41. McLeroy KR, Bibeau D, Steckler A, Glanz K. An Ecological Perspective on Health Promotion Programs. Health Education Quarterly. 1988;15(4):351-77.

42. Mackenbach JP. Politics is nothing but medicine at a larger scale: reflections on public health's biggest idea. Journal of epidemiology and community health. 2009;63(3):181-4.

43. MacDonald TH. Removing the Barriers to Global Health Equity. Oxford: Radcliffe Publishing; 2009.

44. Baum F. Governing for health. Oxford: Ox- 
Why do we need a robust theory of activities?

ford University Press; 2019.

45. Radhakrishnan S. Recovery of Faith. Del-

hi: Hind Pocket Books; 1967.

46. Agarwal A. Reorientation of activities and self-environment integration (ROASEI): A new theory of Human Activities. PsyXiv 8xz5s [Preprint]. 18 July 2020 [cited 18 July 2020]. Available from: 10.31234/osf.io/8xz5s

47. Hyland ME. The Origins of Health and Disease. New York: Cambridge University Press; 2011.

48. Nestle M. Food politics: how the food industry influences nutrition and health. 2nd ed. London, England: University of California Press; 2007. 508 p.

49. Sharma NC. Bidi baron in parliamentary panel irks anti-tobbaco coalition 2015 [updated 27 September, 2015, . Available from: https://www.indiatoday. in/india/story/bidi-baron-in-parliamentary-panel-irks-anti-tobbaco-coalition-265012-2015-09-27.

50. Takano T, Nakamura K, Watanabe M. Urban residential environments and senior citizens' longevity in megacity areas: the importance of walkable green spaces. Journal of epidemiology and community health. 2002;56(12):913-8. 